\title{
Implant Supported Mandibular Overdenture with Bilateral Balanced Occlusion: A Case Report
}

\author{
Maheshwari $\mathbf{R}^{1}$, Hans $\mathbf{S}^{2}$, Mittal $\mathbf{S}^{3}$, Aneja $\mathbf{S}^{4}$, Duhan $\mathrm{J}^{5}$
}

\begin{abstract}
Implant Supported overdentures have been a common treatment for edentulous patients for the past 25 years and predictable achieve good clinical results. Many patients, especially those who are uncomfortable with dentures, enjoy the additional retention and support implants provide for their dentures. The implant-supported overdenture has been accepted as the standard of care for fully edentulous patients and should be the first choice of treatment for the edentulous mandible. Implant-supported overdentures offer many practical advantages over conventional complete dentures and removable partial dentures. These include decreased bone resorption; reduced or eliminated prosthesis movement; better esthetics; improved tooth position; better occlusion, including improved occlusal load direction, increased occlusal function and maintenance of the occlusal vertical dimension. Supported overdentures improve phonetics, the patient's psychological outlook and quality of life. Conventional dentures rely upon the residual alveolar ridge and mucosa for support and retention. Many patients have problems adapting to their complete dentures, especially to the mandibular prosthesis. The widespread use of denture adhesives is one indication that these prostheses generally provide inadequate comfort and function.
\end{abstract}

KEYWORDS: Implant supported overdenture, Overdenture

${ }^{1}$ Senior Lecturer

Dept. of Prosthodontics

Kothiwal Dental College \& Research Centre

Moradabad, UttarPradesh, INDIA

${ }^{2}$ Reader

Department of Periodontics

Maharaja Ganga Singh Dental College \& Research

Center, Sri Ganganagar, Rajasthan, INDIA

${ }^{3}$ Senior Lecturer

Dept. of Orthodontics

JCD Dental College and Hospital, Barnala Road,

Sirsa, Haryana, INDIA

${ }^{4}$ Reader

Dept. of Prosthodontics

Maharaja Ganga Singh Dental College \& Research

Center, Sri Ganganagar, Rajasthan, INDIA

${ }^{5}$ Professor

Dept. of Endodontics and Conservative Dentistry

PGIMS Rohtak, Haryana, INDIA

Sri Ganganagar, Rajasthan, INDIA

\section{Contact Author}

Dr. Suruchi Hans

suruchihans9@gmail.com

J Oral Health Comm Dent 2015;9(1)44-46

\section{INTRODUCTION}

7 he prosthetic management of the edentulous patient has long been a major challenge for dentistry. For well over a century, complete maxillary and mandibular dentures have been the traditional standard of care. However, most patients report significantly more problems adapting to their mandibular denture due to a lack of comfort (eg, they suffer from an increase in pain and soreness), retention, stability, and to the inability to chew and eat. Recent scientific studies (1-3) carried out over the past decade have determined that the benefits of a mandibular two-implant overdenture are sufficient to propose the twoimplant overdenture-rather than the conventional denture-as the first treatment option.

\section{CASE REPORT}

- A Patient reported to the D.Y Patil Dental Hospital, Dept. of Prosthodontics with the chief complaint of missing teeth and wants replacement for same. He has had previous denture but wanted a more stable fitted lower denture. He got his teeth extracted 2 yrs back. He had history of previous denture which had become loose now (lower denture). On Intra oral examination completely healed maxillary and mandibular ridge with adequate width and height were found.

- The treatment options given were

- Set of complete dentures with balanced occlusion

- Implant supported mandibular Overdenture 


\section{INVESTIGATIONS}

Investigations advised: - OPG, BT, CT, Plasma Ca level

\section{TREATMENT}

Treatment part consisted of making conventional sets of upper and lower denture. The procedure consisted of

1. Preliminary impressions of maxillary and mandibular ridge are made using impression compound. Border moulding with green stick and final impressions were made using zinc oxide eugenol paste. Jaw relation and mounting was done, further teeth arrangement was carried out. . Balancing was done so to make denture stable followed by Try in of both upper and lower teeth arrangement was done prior to processing of denture. (fig 1)

2. Radiographic stent was made using gutta percha, OPG was made to see the positions where implant will be placed. 3. Flap was reflected and two single piece implants were placed of $10 \mathrm{~mm}$ in length and $3.3 \mathrm{~mm}$ in diameter at ' $\mathrm{B}$ ' and ' $C$ ' positions. After implant insertion patient was recalled after 2 weeks of osseointegration . Rubber rings were placed on implants and nylon caps on intaglio surface of the lower denture and denture was inserted (fig 2)

\section{DISCUSSION}

Studies (1-3) show implant-supported overdentures have superior retention to conventional dentures. Regardless of the type of attachment system used -- bar, ball or magnet -- patients are significantly more satisfied with implant-supported overdentures than with conventional dentures. Patients find implant-supported overdentures significantly more stable and rate their ability to chew a wider variety of foods as significantly easier, thus improving their nutritional state. Furthermore, they find implant-supported overdentures more comfortable and speech easier. The implant-supported overdenture may reduce the amount of soft tissue coverage and extension of the prosthesis which is especially important for new denture wearers or those

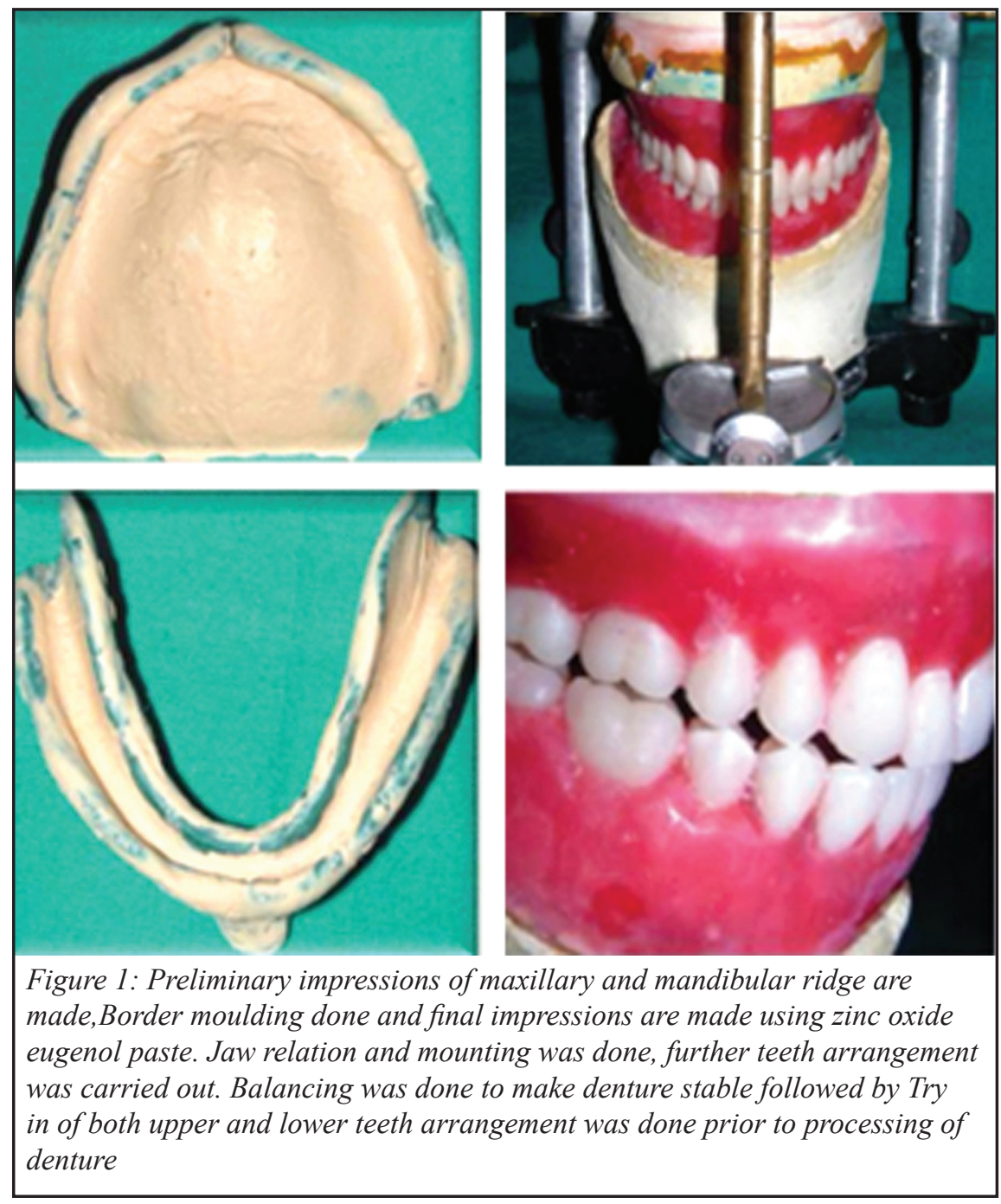

who have low gagging thresholds. The 2002 McGill Consensus Statement cites studies of several populations showing that patients with implant supported overdentures enjoy a significantly higher quality of life than those who wear conventional dentures. The McGill Statement concluded there is overwhelming evidence that the restoration of the edentulous mandible with a conventional denture is no longer the most appropriate choice of prosthetic treatment. The implantsupported overdenture has become the standard of care. Numerous studies $(3,4)$ show cumulative success rates for all implant supported overdentures at 95.4 percent, with implant-supported overdentures placed in the mandible enjoying a slightly higher success rate than implant-supported overdentures placed in the maxilla. The major indications for a mandibular implantsupported over- One advantage of implant-supported full bridges and dentures is that they function like tooth roots, which preserves jaw bone. Dental implants integrate with the jawbone and dramatically reduce the rate of bone loss attributed to conventional dentures.Edentulism is characterized by atrophy of the jaw bone. Studies show rapid resorption -- an average of $4 \mathrm{~mm}$-- occurs during the first year after tooth loss and thereafter decreases to $0.5 \mathrm{~mm}$ per year. Over a five- year period, $5.2 \mathrm{~mm}$ of vertical bone height will be lost under complete dentures. Bone loss under complete dentures continues with the mandible experienc- 

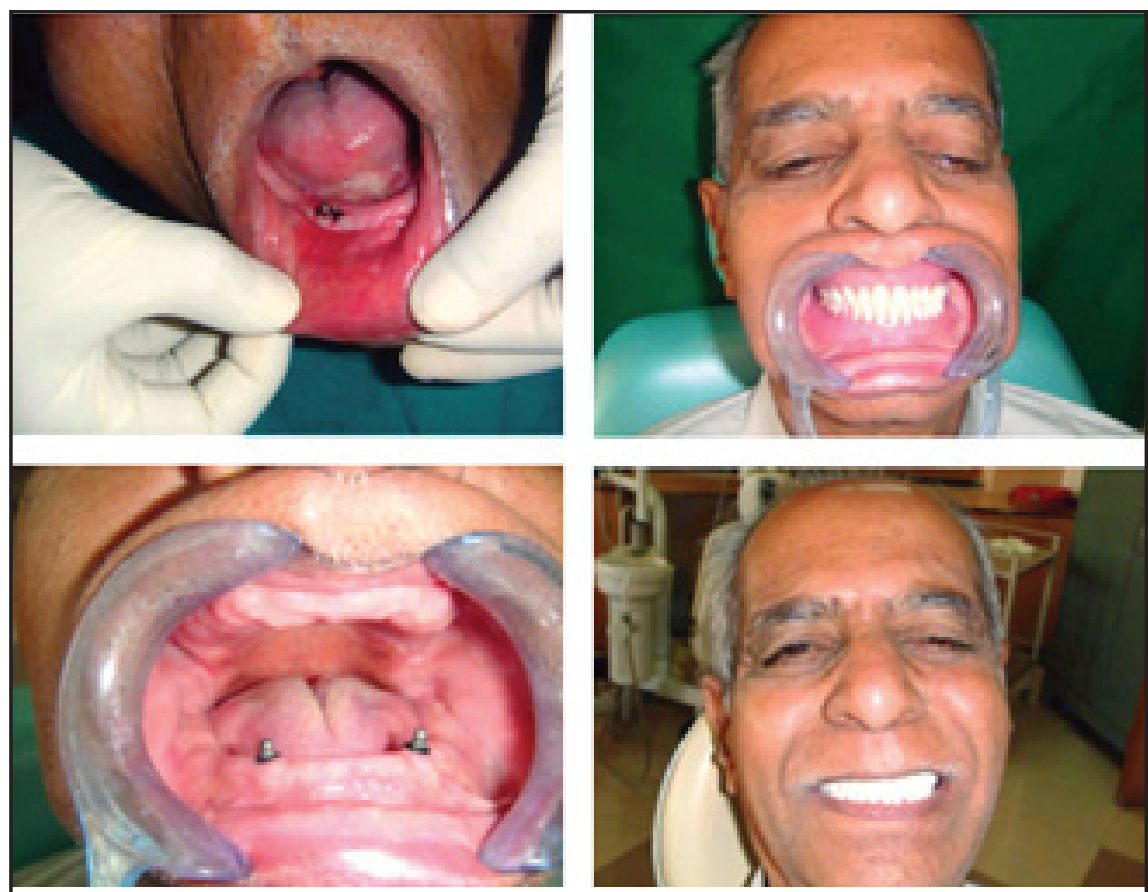

Figure 2: Flap was reflected and two single piece implants were placed of 10 $\mathrm{mm}$ in length and $3.3 \mathrm{~mm}$ in diameter at ' $B$ ' and ' $C$ ' positions. After implant insertion patient was recalled after 2 weeks of osseointegration. Rubber rings were placed on implants and nylon caps on intaglio surface of the lower denture and denture was inserted

ing a fourfold greater vertical bone loss than the maxilla.

In contrast, Schwartz-Arad et al found that 70 percent of their patients with implant-supported overdentures lost less than $.2 \mathrm{~mm}$ bone in the first year. Misch found that only $.6 \mathrm{~mm}$ of bone will typically be lost over a five- year period and long-term resorption may remain as low as $.1 \mathrm{~mm}$ per year in patients with overdentures supported by multiple implants. Crestal bone loss (CBL) around implants supporting overdentures appears to be affected by factors such as location (maxilla or mandible), attachment system, and number of implants supporting the overdenture. Location in the maxilla or the mandible appears to most influence CBL. Studies show implants in the mandible exhibit less CBL than implants in the maxilla, which could be attributed to the difference in bone quality in the maxilla and the mandible and to different loading circumstances. The maxilla normally has less density and quantity of bone than the mandible. The resorbed mandible usually has dense compact bone with an oak-like quality or a combination of thick porous compact bone on the outside and course trabecular bone on the inside. Because the percentage of bone at the implant interface is 70 to 80 percent, mandibular implants are the most successful. The type of bone most commonly found in the long-term edentulous Studies show implant-supported overdentures have superior retention to conventional dentures (3-5).

\section{CONCLUSION}

Implant supported mandibluar overdenture are more stable, mastication was easier and speech dramatically improved. The improvement in diet of those who received the implant supported mandibular overdenture improved their nutritional state and general health, an important consideration for seniors who are vulnerable to malnutrition. Perhaps of greatest significance was the bio-psychosocial enhancement observed in self esteem and social engagement. It can be thus concluded that Implant supported mandibluar overdenture or some variant should become the first choice of treatment for the edentulous mandible.

\section{ACKNOWLEDGEMENTS}

Thankful to Bharati Vidyapeeth Dental College and Hospital, Mumbai and JCD Dental College and Hospital, Sirsa for their help and support.

\section{REFRENCES}

1. Bakke M, Holm B, Gotfredsen K. Masticatory function and patient satisfactionwith implant-supported mandibular overdentures: a prospective 5-year study. International Journal of Prosthodontics 2002;15:575-81.

2. Berretin-Felix G, Nary Filho H, Padovani CR, Trindade Junior AS, Machado WM. Electromyographic evaluation of mastication and swallowing in elderly individuals with mandibular fixed implantsupported prostheses. Journal of Applied Oral Science 2008;16:116-21.

3. Carlsson GE, Lindquist LW. Ten-year longitudinal study of masticatory function in edentulous patients treated with fixed complete dentures on osseointegrated implants. International Journal of Prosthodontics 1994;7:448-53.

4. Hatch JP, Shinkai RSA, Sakai S, Rugh JD, Paunovich ED. Determinants of masticatory performance in dentate adults. Archives of Oral Biology 2000;46: 641-48.

5. Stellingsma K, Slagter AP, Stegenga B, Raghoebar GM, Meijer HJA. Masticatory function in patients with an extremely resorbed mandible restored with mandibular implant-retained overdentures: comparison of three types of treatment protocols. Journal of Oral Rehabilitation 2005;32:403-10. 